\title{
INFLUENCE OF DOUBLE PHASE RECRYSTALLIZATION ON STRUCTURE FORMATION OF CARBON AND TOOL STEELS
}

\author{
F.R. Norkhudjayev ${ }^{*}$, A.A.Mukhamedov ${ }^{1}$, Nabiyev B.N. ${ }^{2}$, Khodjimukhamedova M.M.2, R.F. Norkhudjayeva ${ }^{1}$ \\ ${ }^{I}$ Tashkent State Technical University, Uzbekistan \\ ${ }^{2}$ Andijan Institute of Mechanical Engineering, Uzbekistan \\ Email:fff8uma@mail.ru
}

\begin{abstract}
The paper considers the possibility of using heat treatment with double phase recrystallization of tool carbon and alloy steels. Based on the studies carried out, the peculiarity of the formation of the parameters of the structure of tool steels during high-temperature heating and quenching, intermediate tempering, and final heat treatment is shown. The studies carried out made it possible to establish the regularities of the redistribution of interstitial atoms in a solid solution after double phase recrystallization and their influence on the tempering processes of steels.
\end{abstract}

Keywords: Double phase recrystallization, Defectiveness of the crystal structure; Quenching; Tempering.

\section{Introduction}

Of the total volume of smelted steel, about $25 \%$ are alloyed; a significant proportion of them are tool steel. Reducing the consumption of tool steels, increasing the productivity of metalworking, and reducing costs per unit of production are possible with a significant increase in the durability of cutting and shaping die tools.

Tool steels are divided into non-heat-resistant carbon and alloy steels, semi-heat-resistant and heat-resistant [1]. Heat-resistant steels include highspeed steels and hot-formed die steels. Among these steels, carbon steels are widely used for cutting and punching tools for cold forming, alloyed steels that are not heat-resistant and semi-heat-resistant, they are used for making drills, reamers, taps, dies, combs, broaches, cold heading dies and punches, punching dies, etc. [1-4].

During operation, cutting tools and dies are in a complex stress state and experience high contact stresses (up to $5000 \mathrm{MPa}$ ), shock loads, and thermal effects. The tool requires high hardness, strength, resistance to small plastic deformations, as well as heat resistance, and wear resistance $[5,6]$.

In addition, there are some technical requirements: hardenability, low tendency to deformation, and grindability. The required service properties are hardness, wear resistance, heat resistance, tool steels are obtained after hardening for martensite or after precipitation hardening. Nonheat-resistant steels after quenching with heating above $A_{c 1}$ have $0.6-0.8 \% \mathrm{C}$ in solid solution. Heatresistant and semi-heat-resistant steels are quenched from temperatures significantly higher than Ac1 to dissolve secondary carbides and alloy the solid solution [1]. Low heat resistance carbon and alloyed tool steels, as well as semi heat resistant high chromium steels, are the most widespread. However, the heat resistance of the former does not exceed $200-300^{\circ} \mathrm{C}$, and of the latter, $500^{\circ} \mathrm{C}$. In general, in some cases, the use of these steels may be limited or insufficiently effective due to their low wear resistance.

To increase the service life of tools made of these steels, it is necessary to find the relationship between the parameters of the micro and fine structure and the wear resistance of the alloy. This approach made it possible to develop new technological processes for the heat treatment of steel $[7,8]$. Standard modes of heat treatment of tool steel hardened for martensite include heating to a temperature of $\mathrm{Ac}_{\mathrm{c} 1}+30 \div 50{ }^{\circ} \mathrm{C}$, quenching in water and oil, and subsequent low tempering to the required hardness. In this case, the structure contains fine acicular martensite, secondary carbides behind the eutectoid steel, and residual austenite. High-alloy steels are quenched from temperatures well above the phase transformation point to dissolve the carbides of the alloying elements. Vacation is carried out either for primary or secondary hardness [4-6].

In some cases, to improve the service properties of finished products, preliminary heat treatment is carried out. It includes all modes of heat treatment with multiple phase recrystallization $[9,10]$. It is possible to establish three main directions in the use of pre-treatment to further improve the properties: 
processing associated with the preparation of the main structure of the matrix to obtain superfine grains with repeated heating, the creation of a certain structure, and the preservation of its elements during the subsequent $\alpha_{\phi^{-}-\gamma^{-}} \alpha_{M}$ transformation by affecting a phase that does not undergo significant changes with repeated lower heating. From these positions, the most acceptable is the modes of heat treatment with double phase recrystallization, when the first is high-temperature.

These modes are technologically the most acceptable and have been widely studied for structural steels [10]. The essence of the method lies in the fact that the first phase of recrystallization is carried out from high heating temperatures. Subsequent cooling is carried out either in the air or in oil or water. In this case, there are extreme heating temperatures when, after cooling, a structure with a maximum defectiveness of the crystal structure is formed.

The second phase recrystallization is carried out with heating temperatures $\mathrm{A}_{\mathrm{c} 1}+30 \div 50{ }^{\circ} \mathrm{C}$ or $\mathrm{A}_{\mathrm{c} 3}+$
$30 \div 50{ }^{\circ} \mathrm{C}$, depending on the steel grade, followed by quenching and tempering.

In these studies, the task was set to establish new features of the formation of the structure during double phase recrystallization of high-carbon, alloy, and tool steel and to develop on this basis the modes of their heat treatment, which would increase the durability of the cutting and shaping stamping tool of cold deformation. Ultimately, by such a solution, it is possible to save expensive alloyed tool steels and increase their productivity in the most economical way.

\section{Methods and Materials}

High-carbon tool steel of industrial smelting grades U12A, 9XC, XVG, X12F1 were selected as objects of research.

The selected materials cover eutectoid carbon steels having high hardness, wear resistance, but low hardenability and heat resistance, alloyed steels are not heat-resistant and are high-chromium semi-heat resistant.

Table 1. Chemical composition of the investigated steels

\begin{tabular}{|c|c|c|c|c|c|c|c|c|}
\hline $\begin{array}{c}\text { Steel } \\
\text { grade }\end{array}$ & C & Mn & Si & Cr & W & V & P & S \\
\hline U12A & 1,2 & 0,3 & 0,2 & - & - & - & 0,03 & 0,02 \\
\hline 9XC & 0,9 & 0,4 & 1,3 & 1,0 & - & - & 0,03 & 0,025 \\
\hline XVG & 0,98 & 0,9 & 0,25 & 0,95 & 1,3 & - & 0,03 & 0,03 \\
\hline X12F1 & 1,4 & 0,3 & 0,3 & 11,5 & - & 0,8 & 0,03 & 0,025 \\
\hline
\end{tabular}

Heat treatment modes included double quenching with intermediate tempering. The first hardening was carried out at various heating temperatures, ranging from standard to $1200{ }^{\circ} \mathrm{C}$. The intermediate tempering temperature covered the area from $200{ }^{0}$ to $700{ }^{\circ} \mathrm{C}$ repeated phase recrystallization was carried out with heating to standard heating temperatures for quenching with cooling in water with transfer to nitrate or oil. The final tempering was carried out in the temperature range $160-200{ }^{\circ} \mathrm{C}$ for non-heat-resistant steels and $550{ }^{\circ} \mathrm{C}$ for $\mathrm{X} 12 \mathrm{~F} 1$ steel. In some cases, prenormalization with different heating temperatures was used, followed by re-quenching and tempering.

In all cases, heating for hardening was carried out in salt electrode baths. The holding time was: samples - $3 \div 5$ minutes, and the tool - 3-15 minutes, depending on its size and configuration.

To study the structural and phase transformations of heat-treated steels associated with preliminary and final heat treatment, metallographic, X-ray diffraction, dilatometric, and electron microscopic (replica) analyses were used.
X-ray diffraction analysis was carried out on a DRON-2.0 device using radiation from an iron anode. The shift of the centre of gravity of the X-ray lines (310) $\beta$ (220) $\alpha \alpha$-phase and (311) $\alpha$ y-phase was judged on the change in the crystal lattice parameter; the blurring of the X-ray lines was used to judge the defectiveness of the crystal structure.

The degree of tetragonality of the supersaturated solid solution was determined from the broadening of the X-ray line caused by the splitting of the set of planes $\{211,121\}$ and $\{112\}$.

Dilatometric studies were carried out on a differential Shevenard dilatometer; observed the progress of the decomposition of the solid solution and the temperature intervals of the tempering stages of the steel, depending on its thermal history.

The hardness of the samples and the tool were determined on the TK-2 hardness testers and the microhardness on the PMT-3. Durability tests of cutting tools were carried out in laboratory conditions with longitudinal turning with straight cutters both with the use of cutting fluid (coolant) and without it. 


\section{Research Results}

The level of defectiveness of the crystal structure during preliminary quenching depends on the heating temperature. For U12A, 9XC steels, these temperatures fall at $1150{ }^{\circ} \mathrm{C}$, for XVG steel, at $1000{ }^{0}$ and $1150{ }^{\circ} \mathrm{C}$. The formation of the maximum defectiveness of the crystal structure is associated with the onset of dissolution of sparingly soluble phases of steel. These can be carbides of alloying elements or impurity phases - aluminium nitrides or carbon nitrides, oxygen-containing phases. The onset of dissolution of such phases is characterized by the chemical micro-inhomogeneity of the solid solution, which upon cooling, in the process of the $\gamma^{-\alpha} \alpha$ transformation, leads to an additional increase in the defectiveness of the crystal structure.

After preliminary hardening, an intermediate tempering is carried out. Tempering processes run at different rates depending on the alloyed solid solution. Therefore, the level of defectiveness of the crystal structure of steel in the subcritical temperature range depends not only on the preliminary hardening temperature but also on the tempering temperature.

Phase recrystallization of pre-heat-treated steel (quenching, tempering) provides grain refinement, but it differs depending on the pre-treatment modes.

First, at an insufficiently high temperature of intermediate tempering, austenitic grain growth is observed after repeated phase recrystallization.

Secondly, a sufficiently effective grain refining is observed if the preliminary hardening was carried out either from a standard heating temperature or above $1100^{\circ} \mathrm{C}$.

These circumstances are associated with the fact that after quenching from high temperatures, excess carbides are removed, and when heated above 1100 ${ }^{\circ} \mathrm{C}$, refractory impurity phases dissolve. In this case, repeated phase recrystallization occurs under conditions when there are no effective particles that restrain the growth of austenite grains. A sufficiently high intermediate tempering, providing the precipitation of carbides and impurity phases, eliminates this disadvantage.

Thirdly, high-chromium steel X12F1 has the effect of grain recovery, first described by Academician V.D.Sadovsky. Only the introduction of intermediate tempering above $650{ }^{\circ} \mathrm{C}$ provides grain refinement after repeated phase recrystallization.

X-ray diffraction studies have shown that the effects of inheritance of fine structure parameters are observed during phase recrystallization. Therefore, it is possible to indicate the modes of preliminary heat treatment, when, after repeated phase recrystallization, the highest level of defectiveness of the crystal structure will be observed.
The optimal modes of preliminary heat treatment were reached by the methods of mathematical planning of the experiment. It was found that for steels U12A, 9XC, XVG, the optimum temperature of preliminary hardening is $1150{ }^{\circ} \mathrm{C}$, and the temperature of intermediate tempering is $450{ }^{\circ} \mathrm{C}$ for $\mathrm{U} 12 \mathrm{~A}, 600{ }^{\circ} \mathrm{C}$ for $9 \mathrm{XC}$, and $660{ }^{\circ} \mathrm{C}$ for XVG. Further experiments were limited to these tempering temperatures.

More detailed studies have shown that the optimal modes of heat treatment with double phase recrystallization for tool steels differ significantly from those previously known for structural carbon and low-alloy steels. The highest level of defectiveness of the crystal structure is created at a temperature of the first hardening of $1150{ }^{\circ} \mathrm{C}$ (instead of $1200{ }^{\circ} \mathrm{C}$ ) for U12A, 9XC steels, but 1000 ${ }^{\circ} \mathrm{C}$ and $1150{ }^{\circ} \mathrm{C}$ for XVG steel (Fig. 1).

In steel X12F1, the highest level of defectiveness of the crystal structure is also achieved at temperatures of the first hardening of $1150{ }^{\circ} \mathrm{C}$ and intermediate tempering of $350{ }^{\circ} \mathrm{C}$ and $450{ }^{\circ} \mathrm{C}$. However, these modes could not be used due to the manifestation of the effects of structural heredity and grain recovery during repeated phase recrystallization. The most acceptable was the temperature of the intermediate tempering 650-680 ${ }^{\circ} \mathrm{C}$, which provides the refinement of the austenite grain during the final hardening and a relatively high level of defectiveness of the crystal structure (Fig. 2).

Phase analysis of U12A, 9XC, and XVG steels subjected to heat treatment with double phase recrystallization shows that the amount of retained austenite does not or depends little on the temperature of preliminary hardening and intermediate tempering. The amount of retained austenite in X12F1 steel significantly depended on the temperature of preliminary hardening and intermediate tempering.

Only the introduction of intermediate tempering at $650-680{ }^{\circ} \mathrm{C}$ made it possible to obtain approximately the same level of retained austenite, regardless of the temperature of preliminary hardening.

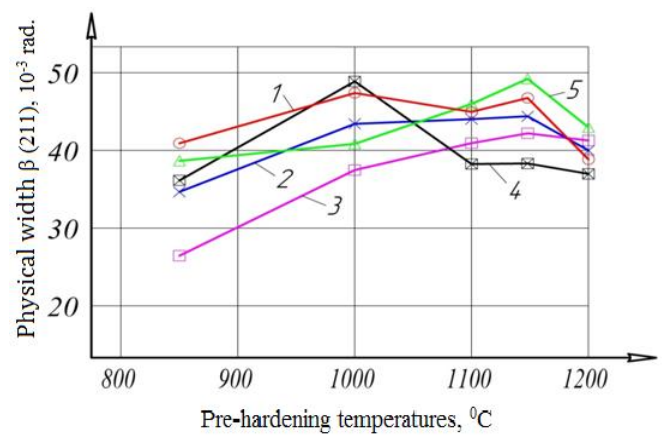

Figure 1: Physical width of the X-ray line (220) of the $X V G$ steel depending on the temperature of prehardening. Intermediate vacation: $1-200^{\circ} \mathrm{C}$, $2-350^{\circ} \mathrm{C}, 3-450^{\circ} \mathrm{C}, 4-600^{\circ} \mathrm{C}, 5-660^{\circ} \mathrm{C}$. 


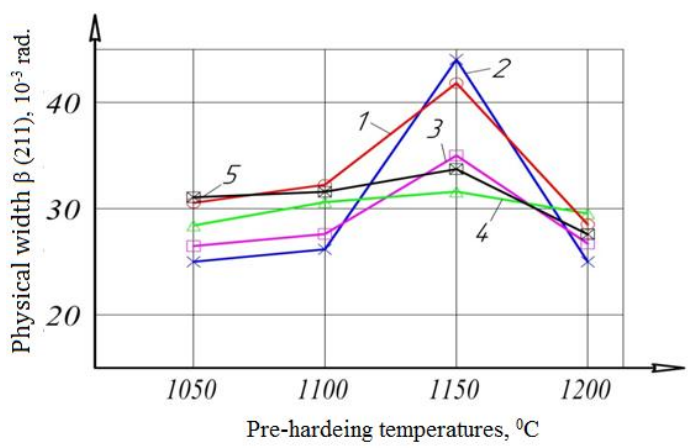

Figure 2: X-ray line width (211) of X12F1 steel depending on the temperature of preliminary hardening. Intermediate vacation: $1-350^{\circ} \mathrm{C}$, $2-450^{\circ} \mathrm{C}, 3-500^{\circ} \mathrm{C}, 4-600^{\circ} \mathrm{C}, 5-650^{\circ} \mathrm{C}$.

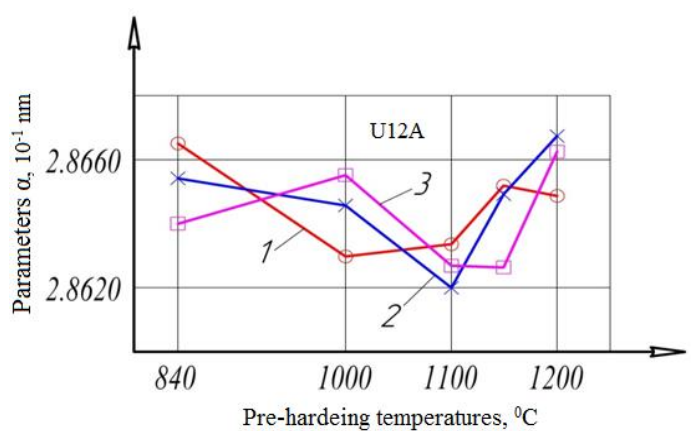

Figure 3: Changes in the lattice parameter of U12A steel depending on the modes of preliminary heat treatment. Intermediate vacation: $1-200^{\circ} \mathrm{C}$, $2-350^{\circ} \mathrm{C}, 3-450^{\circ} \mathrm{C}$.

The modes of preliminary heat treatment are provided for, a significant effect on the redistribution of carbon atoms in the solid solution of the $\alpha$-phase. For steels U12A, 9XC, XVG, regardless of the modes of heat treatment, the amount of carbon in the tetragonal lattice was always less than that determined by chemical analysis and the phase diagram. It is known that in steels with a temperature of the onset of martensitic transformation above room temperature, the process of carbon atoms liberation from the tetragonal lattice occurs already during cooling during quenching. However, the carbon content in the tetragonal solid solution also depended on the preliminary quenching temperature. It was minimal if the preliminary hardening temperature was 1150 ${ }^{\circ} \mathrm{C}$.

The difference in carbon content compared to quenching from the standard temperature reached $0.14+0.33 \%$.

At the same temperatures of preliminary hardening, the minimum value of the crystal lattice parameter was observed (Fig. 3.4).

If we take into account that at a preliminary hardening temperature of $1150{ }^{\circ} \mathrm{C}$ on these steels the maximum level of defectiveness of the crystal structure was observed, then it should be concluded that some of the carbon atoms are additionally transferred to lattice defects.

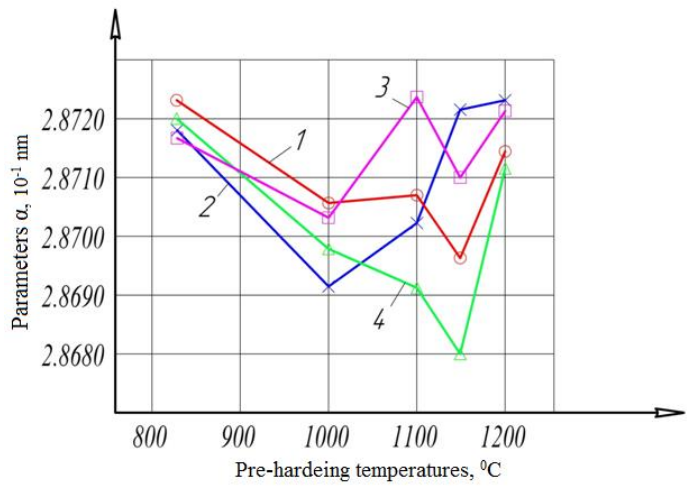

Figure 4: Changes in the lattice parameter of XVG steel depending on the modes of preliminary heat treatment. Intermediate vacation: $1-200^{\circ} \mathrm{C}$, 2- $350^{\circ} \mathrm{C}, 3-600^{\circ} \mathrm{C}, 4-660^{\circ} \mathrm{C}$.

\section{Discussion}

Thus, repeated phase recrystallization of tool steels occurs under conditions of hereditary transfer of fine structure elements of the initial state. This, in turn, causes a redistribution of interstitial atoms during the final heat treatment between the tetragonal lattice and defects in the crystal structure of the $\alpha$ phase.

Dilatometric studies have shown that both after preliminary quenching from different temperatures and after phase recrystallization, one can observe differences in the temperature ranges of the stages of decomposition of the solid solution depending on the heat treatment regimes. The temperature of the beginning of the second stage of decomposition, when the intensive formation of $\varepsilon$-carbide occurs, gets the highest value during quenching from standard temperatures and a temperature of 1150 ${ }^{\circ} \mathrm{C}$. if we take into account that the surface energy density at the interface between the released $\varepsilon$ carbide and the $\alpha$-phase depends on the carbon content in the martensite, then it follows from this:

a) When quenching hypereutectoid steel according to standard modes, the formation of $\varepsilon$ carbide occurs at higher temperatures since part of the carbon is in excess cementite.

b) During preliminary quenching at $1150{ }^{\circ} \mathrm{C}$, a significant part of carbon atoms is located on dislocations, outside the tetragonal lattice; the formation of $\varepsilon$ - carbide also occurs at higher temperatures (table 2).

The volumetric changes during tempering were the smallest if the preliminary hardening temperature was $1150{ }^{\circ} \mathrm{C}$. The last circumstance is important since indicates a lower tendency to deformation during heat treatment.

The temperature ranges of the third stage of decomposition during tempering for U12A and 9XC steels did not depend on the modes of preliminary 
heat treatment. For steel XVG, the temperature ranges of the third stage of decomposition increase slightly with an increase in the preliminary hardening temperature, which indicates a higher alloying of the solid solution.

The heat resistance of the steels under study was determined by the possibility of additional transition of alloying elements into a solid solution during heat treatment with double phase recrystallization. Therefore, the heat resistance of steels U12A, 9KhS did not depend on the modes of preliminary heat treatment. In steel XVG, the heat resistance slightly increases (by $40{ }^{\circ} \mathrm{C}$ ) if the preliminary hardening was above $1100{ }^{\circ} \mathrm{C}$. introduction of preliminary hardening with intermediate tempering into the heat treatment technology of X12F1 steel allows after hardening from $1050{ }^{\circ} \mathrm{C}$, i.e., hardening for primary hardness, observe the effect of secondary hardening at $550{ }^{\circ} \mathrm{C}$ with HRC 60 . Durability tests of cutting and shaping die tools have shown that the state of the steel matrix and the level of defectiveness of the crystal structure have a decisive effect on the wear resistance of the tool.
The tool that had undergone heat treatment according to the optimal modes of preliminary hardening and intermediate tempering had the highest cutting resistance. Heat treatment modes, giving a lower level of defectiveness of the crystal structure, gave a lower tool life (Fig. 5.6).

In comparison with cutters with standard heat treatment, the increase in the resistance of cutters that underwent heat treatment with double phase recrystallization was:

U12A without coolant $-1.47 \div 1.8$ times, with coolant - 1.42-1.8 times; $9 \mathrm{KhS}$ without coolant - $2 \div$ 2.8 times, with coolant - 1.63-2.22 times, CVG without coolant $-1.25 \div 2.5$ times, with coolant 1.17-1.8 times.

Thus, the regularities of the effect of heat treatment with double phase recrystallization on the tool life are observed under different test conditions.

An interesting fact seems to be the fact that higher tool life is achieved at a lower hardness if heat treatment with double phase recrystallization is applied (Fig. 6, b).

Table 2. Temperature ranges of decomposition of martensite during tempering after double quenching

\begin{tabular}{|c|c|c|c|c|}
\hline \multirow{2}{*}{$\begin{array}{l}\text { Pre-hardening } \\
\text { temperature, }{ }^{\circ} \mathrm{C}\end{array}$} & \multicolumn{2}{|c|}{2 - stage temperatures } & \multicolumn{2}{|c|}{3 - stage temperature } \\
\hline & start & $\begin{array}{l}\text { end of the intense } \\
\text { release of } \varepsilon \text { - carbide }\end{array}$ & start & end \\
\hline \multicolumn{5}{|c|}{$\mathrm{U} 12 \mathrm{~A}$} \\
\hline 820 & 115 & 180 & 275 & 380 \\
\hline 1000 & 110 & 175 & 275 & 385 \\
\hline 1100 & 115 & 165 & 275 & 375 \\
\hline 1150 & 115 & 175 & 270 & 380 \\
\hline 1200 & 110 & 165 & 275 & 375 \\
\hline \multicolumn{5}{|c|}{$9 \mathrm{XC}$} \\
\hline 840 & 130 & 200 & 425 & 470 \\
\hline 1000 & 110 & 185 & 425 & 475 \\
\hline 1100 & 115 & 180 & 420 & 475 \\
\hline 1150 & 120 & 190 & 420 & 475 \\
\hline 1200 & 110 & 200 & 420 & 470 \\
\hline \multicolumn{5}{|c|}{ XVG } \\
\hline 840 & 130 & 190 & 315 & 415 \\
\hline 1000 & 120 & 180 & 330 & 430 \\
\hline 1100 & 125 & 185 & 330 & 440 \\
\hline 1150 & 125 & 185 & 330 & 450 \\
\hline 1200 & 120 & 180 & 330 & 450 \\
\hline
\end{tabular}


Establishing the patterns of creating structures with the maximum level of defectiveness of the crystal structure of tool steels during heat treatment with double phase recrystallization makes it possible to develop new technological processes for heat treatment of the tool.

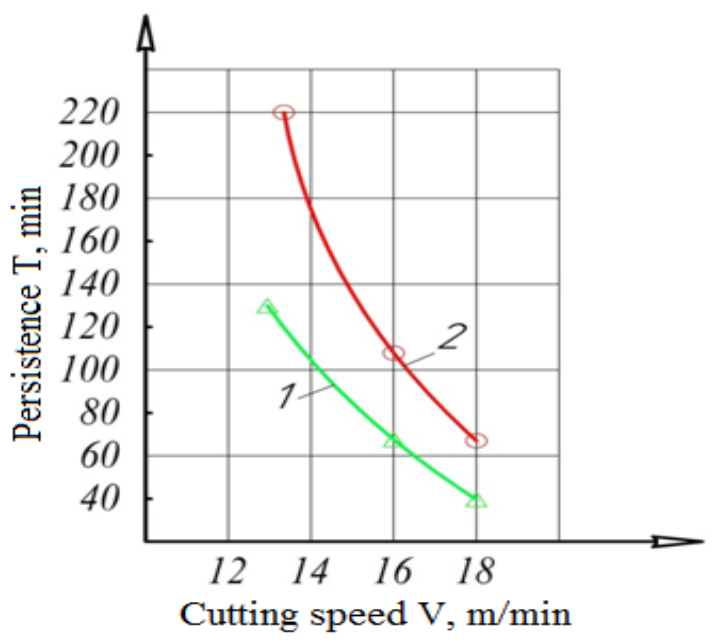

Figure 5: Persistence of cutters made of U12A steel depending on the cutting speed. a - cutting without coolant, $b$ with coolant supply. 1 - cutters are heat-treated according to standard technology; 2 - cutters heat-treated by double hardening with intermediate tempering at $450^{\circ} \mathrm{C}$.

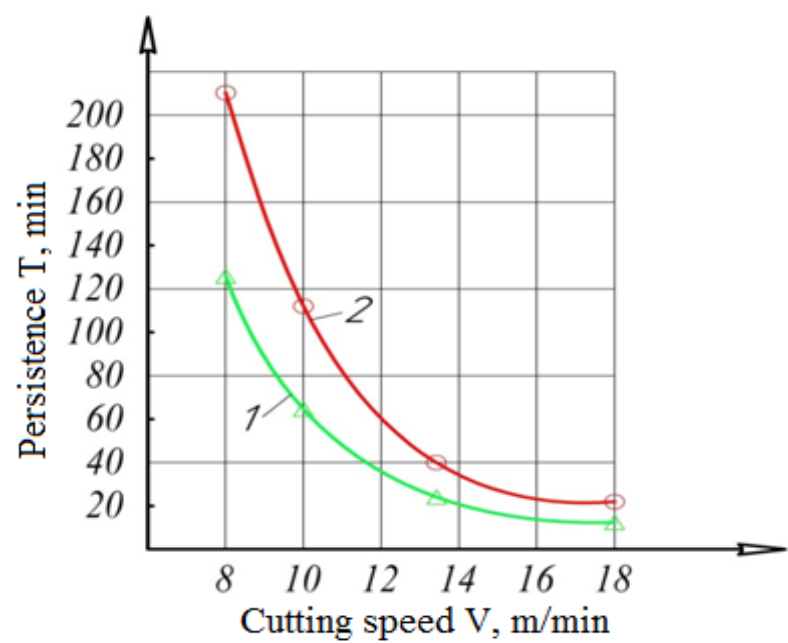

Figure 6. Persistence of cutters made of steel 9XC depending on cutting speed: a - cutting without coolant, $b$ - with coolant supply. 1 - cutters are heat-treated according to standard technology; 2,3 - cutters, heat-treated according to the double hardening mode. 2 - with intermediate vacation $450^{\circ} \mathrm{C}, 3-600^{\circ} \mathrm{C}$ - $\mathrm{HRC} 63,-\mathrm{HRC} 60$.

\section{Conclusions}

1. The most technologically acceptable way to create optimal structure parameters during heat treatment of tool steel is double quenching with intermediate tempering.

2. It is shown that during the first, hightemperature, quenching, there are extreme heating temperatures, when, after cooling, structures are formed with a maximum defectiveness of the crystal structure of the $\alpha$ and $\gamma$ phases. Depending on the alloying of the steel, one or two extreme temperatures are found per $1000^{\circ} \mathrm{C}$ or $1150{ }^{\circ} \mathrm{C}$.

3 . The repeated phase recrystallization of tool steel occurs under conditions of hereditary transfer of elements of the original sub-microstructure. Therefore, after the final heat treatment, it is possible to indicate the extreme temperatures of preliminary hardening, intermediate tempering, giving a maximum defectiveness of the crystal structure. These temperatures fall at $1150{ }^{\circ} \mathrm{C}$ during preliminary hardening, at $450{ }^{\circ} \mathrm{C}, 600{ }^{\circ} \mathrm{C}, 660{ }^{\circ} \mathrm{C}$, 650-680 ${ }^{\circ} \mathrm{C}$ during intermediate tempering of U12A, 9KhS, XVG, and X12F1 steels, respectively.

4. It is shown that a high level of defectiveness of the crystal structure after double quenching with intermediate tempering according to optimal modes contributes to the transition of an additional significant part of carbon atoms (from 0.14 to 
$0.33 \%)$ to lattice defects. This state of the solid solution leads to an increase in the temperature of the onset of the second stage of decomposition of martensite upon tempering the steel.

5. It has been established that the size of the austenitic grain of the tool steel after the final heat treatment depends on the pre-treatment modes. It has a minimum value during preliminary hardening from standard temperatures or heating temperatures of $1125-1150{ }^{\circ} \mathrm{C}$ with intermediate tempering at $450{ }^{\circ} \mathrm{C}, 600^{\circ} \mathrm{C}, 660^{\circ} \mathrm{C}, 650-680{ }^{\circ} \mathrm{C}$ for U12A, 9XC, XVG, X12F1 steels, respectively.

\section{Acknowledgments}

This work was supported by Tashkent State Technical University (TSTU), Andijan Institute of Mechanical Engineering (AIME), Uzbekistan.

\section{References}

[1] Poznyak L. A., Skrinchenko Y.M., Tishaev S.I.; Shtampovie stali [Stamp steels]. M.: Metallurgiya, 1980. -244 s.

[2] Koloskov M. M., Dolbenko E.T., Kashirskii Y.V.; Marochnik staley i splavov [Grading of steels and alloys]. Pod red. Zubchenko A. S. - M.: Mashinostroenie, 2001. - 672 S.

[3] Gurev A.M., Zemlyakov S.A.; Novaya visokoeffektivnaya tehnologiya termicheskogo uprochneniya rejushego i shtampovogo instrumenta [New highly efficient technology for thermal hardening of cutting and punching tools]. $\mathrm{V}$ sb. trudov nauchno-tehnicheskoy konferencii 57 aprelya 2000 g.- Barnaul: Izd-vo AltGTU, 2000.S.25-27.

[4] Geller Y. A. Instrumentalnie stali [Tool steels]. M.: Metallurgiya, 1983. -527 s.

[5] Lahtin Y.M.; Materialovedenie [Materials Science]. M.: Izadelskii dom Alyans, 2009. - 527 s.

[6] Goldshteyn, M.I.; Specialnie stali: Uchebnik dlya vuzov [Special steels: Textbook for universities]. M.: «MISIS», 1999. - 408 s.

[7] Fedulov V.N.; Novie svoystva staley dlya instrumenta holodnogo i goryachego formoobrazovaniya i vozmojnosti ih uprochneniya «Lite i metallurgiya» [New properties of steels for cold and hot forming tools and the possibility of their hardening «Casting and Metallurgy»]. №2(91), 2018. -S.119-123.
[8] Berdiyev D.M., Yusupov A.A., Umarova M.A.; Increase of abrasive wear resistance of steels by thermal processing // International Journal of Advanced Research in Science, Engineering and Technology. Vol. 5, Issue 9, September 2018. P. 6851-6854.

[9] Erkin, U., Umidjon, M., \& Umida, S. (2021, September). Application of Magnetic Field on Lubricating Cooling Technological Condition in Metal Cutting Process. In International Conference on Reliable Systems Engineering (pp. 100-106). Springer, Cham.

[10] Berdiev D.M., Yusupov A.A.; Povishenie iznosostokosti zubev zubchatyh koles ciklicheskoy zakalkoy s indukcionnim nagrevaniem [Increasing the wear resistance of gear teeth by cyclic hardening with induction heating] // Vestnik mashinostroeniya, - Moskva: 2020. - №3. - S. 50-53.

[11] Norkhudjaev F.R., Mukhamedov A.A., Khudayberdiyev O.R., Ergashev D.M., Djalolova S.T.; Technological capabilities of application of thermocyclic processing (tcp) tool steel. International Journal of Psychosocial Rehabilitation, Vol. 24, Issue 08, 2020, and ISSN: 1475-7192, - India: 2020. - P. 1866-1874.

[12] Norkudjayev F. R. Alikulov A. Kh. Abdurakhmonov Kh. Z. Tursunov T. Kh. Examination of Thermophysical Processes in the Creation of Metal Layered Compositions. International Journal of Recent Technology and Engineering (IJRTE) ISSN: 2277-3878, Volume-8 Issue-2S10, September 2019. P 361-366.

https://www.scopus.com/record/display.uri?eid=2-s2.085075285756\&origin $=$ AuthorNamesList \&txGid $=5 \mathrm{e}$ 9426dea9148b5d4943f35d019901c5

[13] Norkhudjayev Fayzulla Ramazonovich, Mukhamedov Azad Anvarovich, Teshaboyev Abduvakhob Marifovich, Usmonov Jasur Muminaliyevich, Parmonov Sarvar Toshpulatovich. RESOURCE-SAVING MANUFACTURING TECHNOLOGIES AND THERMAL HARDENING OF MACHINE PARTS AND TOOL. International Journal of Mechatronics and Applied Mechanics (IJOMAM), 2021, Issue 9, and ISSN: 2559-6497, P 137-145. 